\title{
Práticas e desafios na preparação da produção em projetos de novos produtos de higiene pessoal
}

\author{
Felipe Botta Tarallo WHIRLPOOL S.A.
}

Daniel Capaldo Amaral EESC/USP

\section{RESUMO}

A literatura sobre o processo de desenvolvimento de produtos (PDP) dedica pouca atenção à etapa de preparação dos meios de manufatura. Em certos produtos, porém, o diferencial tecnológico está justamente no processo de fabricação. É o caso de bens de consumo que se caracterizam pela produção em alto volume, predominando processos produtivos com elevado nível de automação. Este trabalho apresenta um estudo de caso em um produtor de bens de consumo para higiene pessoal, cuja característica principal é o volume de produção elevado. Partindo de uma análise detalhada do PDP, demonstram-se a importância desta etapa, as dificuldades enfrentadas pela empresa e questões de pesquisa relevantes. A análise contemplou a modelagem do processo de negócio, entrevistas com os principais atores e análise documental. Além de apresentar e discutir a experiência da empresa estudada, descrevem-se lacunas importantes na teoria gestão do desenvolvimento de produtos e recomendações para pesquisas futuras.

\section{Practices and barriers in the manufacturing preparation of new products at a personal hygiene product enterprise}

\begin{abstract}
The new product development process (PDP) literature doesn't give significant focus on manufacturing process specification and validation. Nevertheless, in some areas this subject is one of the main competitive advantage sources. The consumer goods industry that's related with high production level is an example. This paper presents a case study about an especific consumer goods producer from personnel higienic segment. It demonstrates the importance of this product development phase, the barriers, and the theoric gap, applying a business process modelling approach. The annalysis was based on the product development process model elaborated, interviews with stakeholders, documental analysis and participant observation. Besides presenting and discussing this enterprise experience, the paper brings an actual theory annalysis and future research statements.
\end{abstract}

\section{KEY WORDS}

Product development process, product validation, design for manufacture and assembly. 


\section{INTRODUÇÃO}

A importância estratégica do Processo de Desenvolvimento de Produtos (PDP) para a competitividade das empresas tem sido enfatizada por muitos autores. $\mathrm{O}$ foco principal dos estudos, porém, se dá nas etapas iniciais do processo, apesar de a preparação dos meios de manufatura mostrar-se crítica para determinados tipos de produtos.

Isso acontece quando a criação do novo produto é determinada e limitada pelas possibilidades tecnológicas dos processos produtivos disponíveis. Nesses casos, o sucesso no desenvolvimento depende fundamentalmente do projeto dos meios de fabricação. As unidades funcionais como as de engenharia de manufatura passam a ter um papel tão ou mais decisivo que o das áreas tradicionais como engenharia de produto, $\mathrm{P} \& \mathrm{D}$ ou marketing.

Desenvolver processos de fabricação capazes é fundamental também no caso de mercados regulados por agências, tais como o FDA (Food and Drug Administration) e ANVISA (Agência Nacional de Vigilância Sanitária). Elas exigem procedimentos de validação de processos de fabricação que gerem evidências concretas da eficácia quanto a diversos fatores, como: ergonomia, segurança, meio ambiente, eficiência, estabilidade, confiabilidade de software, planos de manutenção, etc. A empresa precisa comprovar que tem condições de assegurar a qualidade dos produtos fabricados em escala.

A literatura sobre gestão do desenvolvimento de produtos, porém, é escassa nesta área. Há uma grande variedade de técnicas e métodos para identificação de requisitos, geração de concepções de produtos e detalhamento do produto, e poucos dedicados aos problemas do projeto dos processos de fabricação.

O trabalho contribui para o preenchimento desta lacuna, analisando profundamente as atividades de preparação da manufatura do processo de desenvolvimento de produto de uma empresa que se enquadra nas condições acima citadas: produz bens de consumo para a área de higiene pessoal, em grande volume, com processo altamente automatizado e cujo mercado é regulado pelas agências FDA e ANVISA. O projeto dos processos de fabricação é a etapa mais significativa no PDP da empresa, em custo e esforço (horas de trabalho), e é essencial para garantir a viabilidade econômica e eficiência do produto; portanto, sua competitividade. $\mathrm{O}$ trabalho descreve o processo utilizado pela empresa e as dificuldades identificadas na forma de oportunidades de melhoria. Empregou-se um método de modelagem de processos de negócio e, por isso, incluiu-se um referencial teórico básico sobre o assunto, além da apresentação do estado da arte da preparação dos meios de manufatura.

\section{A ETAPA DE PREPARAÇÃO DOS MEIOS DE MANUFATURA DO PDP}

Desenvolvimento de produto pode ser definido como um processo, conjunto de atividades, pelo qual uma organização transforma dados sobre oportunidades de mercado e possibilidades técnicas em bens e informações para a fabricação de um produto comercial (CLARK; FUJIMOTO, 1991). Ele abrange as funções de marketing, engenharia de produto, produção e demais áreas de uma empresa.

Esta definição pioneira marcou o início da utilização da abordagem de processos na área de gestão do desenvolvimento de produto. Na última década, porém, ela se expandiu incluindo atividades de planejamento estratégico (WHEELWRIGHT; CLARK, 1993) e atividades de acompanhamento da produção e retirada do produto do mercado (ROZENFELD et al., 2006).

\section{trabalho descreve o processo utilizado pela} forma de oportunidades de melhoria.

Os textos clássicos de gestão de desenvolvimento de produto apresentam diferentes modelos de fases e etapas: Clark e Fujimoto, 1991; Pugh, 1978; Wheelwright e Clark, 1993; Cooper, 1993; Clausing, 1994; Ulrich e Eppinger, 1995; Ullman, 1997; Baxter, 1998; e Rozenfeld et al., 2006.

Analisando-os é possível perceber que a etapa de preparação da produção é pouco explorada; apesar de sua importância ser mencionada constantemente pelos autores citados. Aliás, o trabalho pioneiro de Clark e Fujimoto (1991) sobre PDP na visão por processo alertava para esse aspecto, que aparece como uma das vantagens competitivas identificadas.

Um exemplo representativo desse comportamento geral é o modelo de stage-gates proposto por Cooper (1993), que descreve a introdução do produto na fábrica na fase denominada de teste e validação do produto. Analisando-se as atividades propostas pelo autor, nota-se uma ênfase nas atividades de verificação da aceitação do produto no mercado e, portanto, da sua validação junto aos consumidores, considerando-se seu desempenho e preço. Quanto à introdução do novo produto na fábrica, o autor cita a atividade de Produção Piloto ("para testar, solucionar bugs, e provar o 
processo de produção, e para determinar mais precisamente custos de fabricação"), sem entrar em detalhes e deixando de lado aspectos importantes das máquinas como segurança, manutenção, etc. Também não discute quais atividades são relevantes para o desenvolvimento dos meios de fabricação do novo produto, ou dificuldades, conflitos e caminhos que possivelmente são enfrentados durante esta etapa.

Três das abordagens citadas oferecem uma atenção maior: as de Wheelwright e Clark (1993), Clausing (1994) e Rozenmodelo de fases para o PDP, modelo de funil. Nele há uma descrição da importância dos testes do processo produtivo, incluindo-se as atividades clássicas de produção piloto, definição de custos de fabricação e debugging. Os autores mencionam casos de conflito entre áreas de desenvolvimento do produto em si e de desenvolvimento dos meios de produção. feld et al. (2006). Wheelwright e Clark (1993) apresentam um

parâmetros e as faixas de valores que deveriam variar para que o desempenho do produto seja ótimo e à prova de influências dos meios de produção. Segundo o autor, seria possível identificar, também, valores ótimos para as especificações de produto e dos processos de fabricação principais. A otimização deveria ocorrer ao longo do processo de desenvolvimento, garantindo que o produto seja projetado de maneira ótima (com desempenho e processos de fabricação robustos). Assim, a otimização do processo é realizada junto com a otimização do produto: evitando problemas na fase de introdução do produto na fábrica.

Este tema está sendo novamente abordado na literatura sob o rótulo do Seis Sigma. A base da metodologia de Projeto Seis Sigma (Design for Six Sigma - DFSS) proposta por Creveling et al. (2003), um dos autores mais representativos no tema, é a integração da gestão de parâmetros críticos com as atividades do processo de desenvolvimento de produtos.

Rozenfeld et al. (2006) apresentam um modelo de desenvolvimento de produto no qual se enfatiza a importância do projeto voltado para a manufatura, com ênfase nas fases iniciais. Dá-se o nome de Preparação da Produção a essa etapa, constituída por atividades de otimização e validação do processo produtivo. A diferença é que inclui aspectos e técnicas voltadas para a ergonomia e o meio ambiente;

A solução apontada é o teste e a validação dos projetos antes que esforços substanciais sejam empregados ou a produção comercial seja iniciada. Eles enfatizam, também, o projetar certo da primeira vez, por meio de um esforço maior nas etapas iniciais do processo. Entretanto, não descrevem como fazê-lo. Adicionalmente, recomendam o registro da aprendizagem adquirida durante esta fase, visando o aproveitamento futuro das soluções encontradas.

O livro de Clausing (1994) também se destaca pela ênfase na preparação da produção. Embora o texto seja mais conhecido por seu papel na difusão da metodologia do QFD. Analisando-o criteriosamente, é possível constatar igual importância na otimização dos produtos quanto à manufaturabilidade e robustez. $\mathrm{O}$ autor descreve o que ele denominou de parâmetros críticos. Na verdade, uma sistematização da teoria de projeto robusto (Robust Design) desenvolvida por Taguchi (consulte PHADKE, 1989). Um parâmetro crítico é uma dimensão física do funcionamento do produto que influencia, de maneira significativa, o seu desempenho. Ele está relacionado com o princípio de solução e é igual para todos os produtos que fazem uso deste princípio.

Realizando experimentos, seria possível identificar esses além da tradicional preocupação com a manufaturabilidade expressa pelos demais autores. Os autores citam ferramentas para o desenvolvimento de produtos que podem auxiliar nesse desafio. As principais, segundo o modelo dos autores, são: o projeto para a manufatura e montagem (Design for Manufacturing and Assembly - DFMA) e similares (Design for $X$ ), conjunto de boas práticas para projeto visando a manufatura, montagem, segurança, meio-ambiente, etc.; a metodologia de análise do modo e efeito de falha (FMEA); e o controle estatístico de processo (CEP), que permite validar os processos de fabricação.

Ozer (1999) realizou um estudo sobre os diferentes modos de se avaliar metodologicamente (com relação aos mais variados aspectos) a viabilidade de ir em frente ou não com o desenvolvimento de um produto, para os diferentes estágios do processo de desenvolvimento de novos produtos. O autor cita como um modelo clássico para avaliação de novos produtos aquele conduzido em cinco estágios, incluindo teste do conceito, teste do protótipo, pré-teste de mercado, teste de mercado e lançamento, sempre sob a óptica da rentabilidade financeira (em termos de volume de vendas, expansão de um mercado, aceitação entre 
consumidores e etc). Mas o referido estudo não apresenta nada a respeito da avaliação de novos produtos do ponto de vista do ambiente de fabricação. Por exemplo, critérios que garantissem a viabilidade de se atingir o mínimo de qualidade requerida.

Já Muller e Fairlie-Clarke (2003) afirmam que o desenvolvimento do processo e dos meios necessários para a fabricação de um produto são temas fundamentais para o PDP. Eles propõem um método de avaliação do que consideram requisitos para a manufatura e para a cadeia de suprimentos dos novos produtos. O objetivo do método proposto é medir o potencial dos modelos de PDP quanto à manufaturabilidade. Um dos resultados é a identificação de que as atividades e temas relativos à manufatura do novo produto são de alta importância para um desenvolvimento de sucesso. Um aspecto interessante é que os autores atribuem a pequena ênfase dada ao tema na literatura da área à hipótese de que os profissionais de PDP acreditem que tais atividades sejam menos problemáticas e mais fáceis de serem realizadas.

Park \& Baik (1999) reforçam a importância de se incorporar considerações sobre fabricação nas fases iniciais do projeto do produto. Enfatizam que a cooperação é fator essencial para o projeto dos meios de manufatura. Os autores descrevem um modelo para aplicação de DFM (Design for Manufacturability), integrado a um sistema de aprendizado e comunicação baseado na Internet. Trata-se do trabalho que mais se aproxima do tema deste artigo, onde há uma busca na integração entre a metodologia DFM e as atividades do processo de desenvolvimento de produto com aprendizagem e a técnica de projeto para a manufatura e montagem. No entanto, é um trabalho teórico. Propõe-se um sistema de informação particular e não se investigam os problemas reais enfrentados pelas empresas.

\section{MODELAGEM DE PROCESSOS DE NEGÓCIO}

A abordagem de gestão por processos, iniciada com a manufatura integrada por computador e com a reengenharia, é hoje empregada nas diversas áreas da administração, tais como qualidade, implantação de sistemas de informação e outras (CRUZ, 2003). Um modelo de processo de negócio, também chamado de modelos de empresa, é um mapa, uma representação que visa descrever as diferentes visões da empresa. Conforme Vernadat (1996, p. 71), "um modelo de empresa é um conjunto consistente e complementar de modelos descrevendo vários aspectos de uma organização e que tem por objetivo auxiliar um ou mais usuários de uma empresa em um propósito específico".
Segundo Benedicts, Amaral e Rozenfeld (2003), existem vários métodos de representação capazes de descrever as diferentes visões de um processo organizacional. A melhor forma de proceder é encontrar o método de modelagem, ou o conjunto deles (framework), mais adequado conforme o uso que se fará do modelo (BENEDICTS; AMARAL; ROZENFELD, 2003).

Um dos métodos de representação disponíveis é o SADT (Structured Analysis and Development Technique), desenvolvido por Douglas T. Ross num projeto de desenvolvimento de uma linguagem estruturada para programação de máquinas-ferramenta, no MIT, no fim da década de 1960 (MARCA; MCGOWAN, 1997). Esse formalismo trazia algumas características revolucionárias que auxiliaram sobremaneira a descrição e desenvolvimento dos softwares complexos de automação. São elas a decomposição funcional e o fato de possuir uma representação esquemática simples. Essas características auxiliaram na disseminação desse formalismo.

\section{MÉTODO}

\subsection{Objetivo do Trabalho}

O objetivo principal é descrever as atividades realizadas pela empresa durante o projeto dos meios de produção, as dificuldades encontradas e ações planejadas para melhorar o desempenho nesta etapa. A contribuição está na comparação desses problemas e soluções com a teoria sobre o assunto citada no item 2.

\subsection{Classificação do método}

O método pode ser classificado como um estudo de caso único. Segundo Yin (2001), uma investigação empírica que trata um fenômeno contemporâneo em seu contexto real, especialmente útil quando as fronteiras entre o fenômeno e o contexto não estão totalmente claras. O nível de detalhe desse método pode ser considerado elevado em comparação com outros métodos, como o survey e os casos múltiplos. A estratégia está coerente com Gil (1991), que recomenda o estudo de caso, e poucas unidades de análise, nas investigações intencionadas a realizar estudos detalhados de um tema.

O envolvimento do pesquisador foi intenso. As atividades foram realizadas no decorrer de um estágio, realizado na área de Engenharia de Manufatura da empresa, com duração de 6 meses e média de 20 horas de trabalho por semana. Durante o período, o pesquisador realizou atividades rotineiras relacionadas aos projetos em desenvolvimento pela empresa, em paralelo com as ações de pesquisa. Os envolvidos sabiam 
tratar-se de um estagiário que conduzia a pesquisa em paralelo com suas atividades.

Uma característica do estudo é a utilização da abordagem de processos de negócio. Para garantir essa perspectiva, empregou-se a modelagem de empresa como um dos instrumentos de pesquisa, visando auxiliar a organização e confrontação dos dados coletados pelas demais fontes: observação participante, entrevistas e análise documental.

\subsection{Etapas da pesquisa}

As etapas utilizadas na condução da pesquisa foram:

1. Identificação do ambiente e etapas gerais do processo de desenvolvimento de produtos da empresa. Deu-se início ao trabalho com a atuação do pesquisador junto ao grupo denominado aqui de Engenharia de Manufatura, auxiliando em pequenas tarefas de projetos realizados pelo grupo. O objetivo foi o entendimento do funcionamento da empresa. Isso foi feito por meio de observações, coleta de relatos dos funcionários e análises de documentos, registrados no diário da pesquisa. A principal fonte de documentos foi o conjunto de procedimentos e normas internos, incluindo o modelo de referência para o processo de desenvolvimento de produto.

2. Escolha e personalização do método de modelagem. $\mathrm{O}$ pesquisador propôs a abordagem de processos de negócio à equipe. Após explicar o conceito, realizou a escolha do método e ferramenta de modelagem em conjunto com o profissional responsável pela área na empresa. A metodologia de modelagem deveria possibilitar uma representação com boa qualidade visual e de fácil leitura e compreensão. Optou-se pela metodologia SADT, cujo formalismo foi adaptado para contemplar padrões presentes na própria empresa. Detalhes da técnica podem ser obtidos em Marca \& McGowan (1997) e Cruz (2003).

3. Escolha da ferramenta de modelagem. A ferramenta de modelagem selecionada foi o Microsoft PowerPoint. Dois fatores principais guiaram a decisão: a qualidade gráfica, considerada suficiente, e a disponibilidade. Praticamente, todas as estações de trabalho da empresa possuíam o sistema instalado.

4. Elaboração do modelo e entrevistas. Finalizadas as etapas anteriores, o pesquisador construiu a primeira versão do modelo de processo sintetizando as informações levantadas até então. Entrevistas com um representante de cada ator principal do processo ajudaram a elucidar detalhes específicos. Participaram das entrevistas: gerente da área de desenvolvimento, engenheiros de processo, engenheiros de manufatura e time de validação de máquinas. Cada entrevista foi individual e durou em média duas horas, durante as quais cada participante descrevia o processo de desenvol- vimento de novos produtos. Disfunções e melhores práticas eventualmente citadas foram também registradas.

5. Identificação de disfunções e melhores práticas. Com o modelo desenvolvido, buscou-se compilar os problemas do processo de negócio a partir da análise do modelo e informações coletadas durante a sua construção. Tais informações foram acrescidas ainda de experiências adicionais vivenciadas pelo pesquisador e de novos relatos (observação participante registrada no diário).

6. Organização e Análise dos Resultados. O desafio desta estapa foi compilar todo o material disponível de maneira a sintetizar as oportunidades de melhoria existentes no processo de negócio. Gerou-se uma tabela com a seguinte estrutura:

- oportunidades de melhoria - Descrição da oportunidade de melhoria identificada;

- possível solução - Proposta de soluções para cada oportunidade de melhoria identificada;

- modelo - Código das atividades do modelo relacionadas à oportunidade de melhoria.

7. Validação do modelo de referência, oportunidades de melhoria e proposição de ações. O objetivo desta etapa foi validar os resultados com a equipe, de forma a garantir que nenhuma distorção fosse cometida, obtendo-se uma visão consensual do problema. O conteúdo do diagnóstico foi apresentado aos diversos atores, em uma reunião conjunta. Novas contribuições e correções foram adicionadas no modelo de processo desenvolvido. Participaram: quatro engenheiros de processos de manufatura; três coordenadores de engenharia de manufatura; um gerente de engenharia de manufatura; e o gerente da fábrica. $\mathrm{O}$ resultado da iniciativa foi extremamente positivo. A reunião gerou uma discussão construtiva acerca dos pontos levantados e, ao final, todos concordaram que se tratava de uma descrição próxima da realidade.

8. Encerramento da pesquisa. Uma nova versão da tabela síntese do diagnóstico foi criada, incorporando contribuições e observações realizadas durante a reunião. Além de ser utilizado na pesquisa, este resultado serviu de base para o gestor responsável pelo processo de desenvolvimento de produtos da empresa. Os dados foram confrontados com a teoria, obtendo-se as conclusões.

\section{DESCRIÇÃO DA EMPRESA}

A empresa analisada pode ser considerada grande segundo os parâmetros do SEBRAE, e seus produtos cobrem um vasto ramo de utilidades. O presente estudo desenvolveu-se na unidade de negócio de produtos higiênicos pessoais, 
mais especificadamente, absorventes higiênicos externos para períodos menstruais e intermenstruais. O trabalho foi desenvolvido dentro do setor funcional de Engenharia de Manufatura da unidade de negócio citada, considerando-se as interfaces com os demais setores funcionais da empresa.

O processo de desenvolvimento de um absorvente higiênico confunde-se com o processo de desenvolvimento dos meios de manufatura, uma vez que a produção desse tipo de produto se dá por meio de um processo de fabricação que pode ser caracterizado na interface entre intermitente e contínuo (SLACK et al., 1997). Isto é, embora haja um momento exato em que se pode identificar o início e o fim da produção de cada produto, caráter intermitente, a produção se dá em volume significativo (centenas de unidades por minuto), com equipamentos totalmente automatizados, nos quais inclusive a alimentação da matéria-prima é realizada e controlada pela máquina, conferindo características típicas de um processo contínuo. A fabricação desses produtos é baseada em diversas tecnologias, como corte (por meio de facas cilíndricas), manipulação (como aplicação de cola, dobra, e etc.) e outras. Os produtos são transferidos de uma etapa a outra por meio de esteiras e dentro de proteções que evitam o contato com os operadores. São fabricados continuamente e embalados automaticamente.

Parte significativa do esforço de desenvolvimento de novos produtos está, portanto, no desenvolvimento do processo de fabricação em si, assim como as características e limitações de tais produtos e as inovações.

O processo de desenvolvimento de produtos da empresa inicia-se, na maior parte dos casos, com especificações da área funcional de Pesquisa e Desenvolvimento, que busca atender necessidades previamente identificadas pela área de Marketing. A partir daí, a Engenharia de Manufatura é envolvida para avaliar a possibilidade de adaptação dos meios de fabricação já existentes ou se há necessidade de desenvolver novos meios de fabricação.

O desenvolvimento de novos produtos é orientado por um modelo de desenvolvimento global ainda não plenamente "institucionalizado" na unidade analisada, segundo a definição de institucionalização de processos apresentada por Chrissis et al. (2003). Isso quer dizer que, embora haja um padrão formal a ser seguido, parte estava sendo praticada de maneira consistente e outra não. $\mathrm{Na}$ época da pesquisa, a liberação do processo produtivo era fortemente institucionalizada, sendo, inclusive, parte do Sistema de Garantia da Qualidade - certificado segundo a série de normas ISO 9000. O restante do desenvolvimento, incluindo-se o desenvolvimento de tecnologia, não fazia parte do escopo do Sistema de Garantia da Qualidade e, embora possuísse um modelo, não havia um padrão consistente de fato; o cumprimento das etapas e ferramentas variava conforme a equipe de projeto. 
sicamente a geração e concepção de idéias e fica a cargo das áreas de Marketing e Pesquisa.

Na segunda etapa do modelo "Projetar/Instalar Processos de Fabricação", foram identificadas 36 atividades, que envolvem basicamente projeto, especificação e aquisição de itens e equipamentos, além de montagem, instalação e correção de problemas (debugging). Há dois fluxos distintos nesta fase, um para o projeto de máquina desenvolvido internamente e outro para o caso de uma aquisição externa da máquina ou pacote de soluções. Esta segunda etapa do modelo corresponde à fase 3 do modelo de PDP oficial da empresa.

A terceira etapa do modelo "Validar Processo" é composta por 27 atividades e também está inserida dentro da fase 3 do modelo oficial da empresa. A etapa de "Validar Processo" corresponde à parte do modelo que descreve os procedimentos adotados para tornar válido um processo produtivo recém-desenvolvido. Esse "tornar válido" inclui desenvolver toda documentação (definida pela política de qualidade da empresa), que compreende uma série de testes e checklists sobre os mais diversos aspectos relacionados a uma máquina produtiva, como segurança, ergonomia, robustez, planos de manutenção, spare parts, dentre outros, além de aspectos relacionados à qualidade (aspectos que comprovem a capacidade do processo de produzir produtos dentro das especificações técnicas). Resumindo, essa etapa do modelo descreve as atividades desenvolvidas para que a área de Engenharia de Manufatura efetivamente comprove a capacidade produtiva e de operação do que foi desenvolvido.

De acordo com a política de qualidade da empresa, um produto só pode ir ao mercado se toda a documentação para a máquina que o originou estiver concluída e assinada por todos os membros do Time de Validação, equipe constituída por profissionais das cinco áreas funcionais envolvidas no desenvolvimento: Engenharia de Manufatura, Qualidade, Manufatura, Segurança (que envolve também Ergonomia e Meio Ambiente) e Pesquisa e Desenvolvimento.

A etapa de Validar Processo está dividida em duas partes: primeiramente há uma validação do processo de fabricação com relação a aspectos de instalação e operação da máquina (considerando-se, portanto, se há o atendimento aos requisi-

\section{Desenvolver Processos de Fabricação}

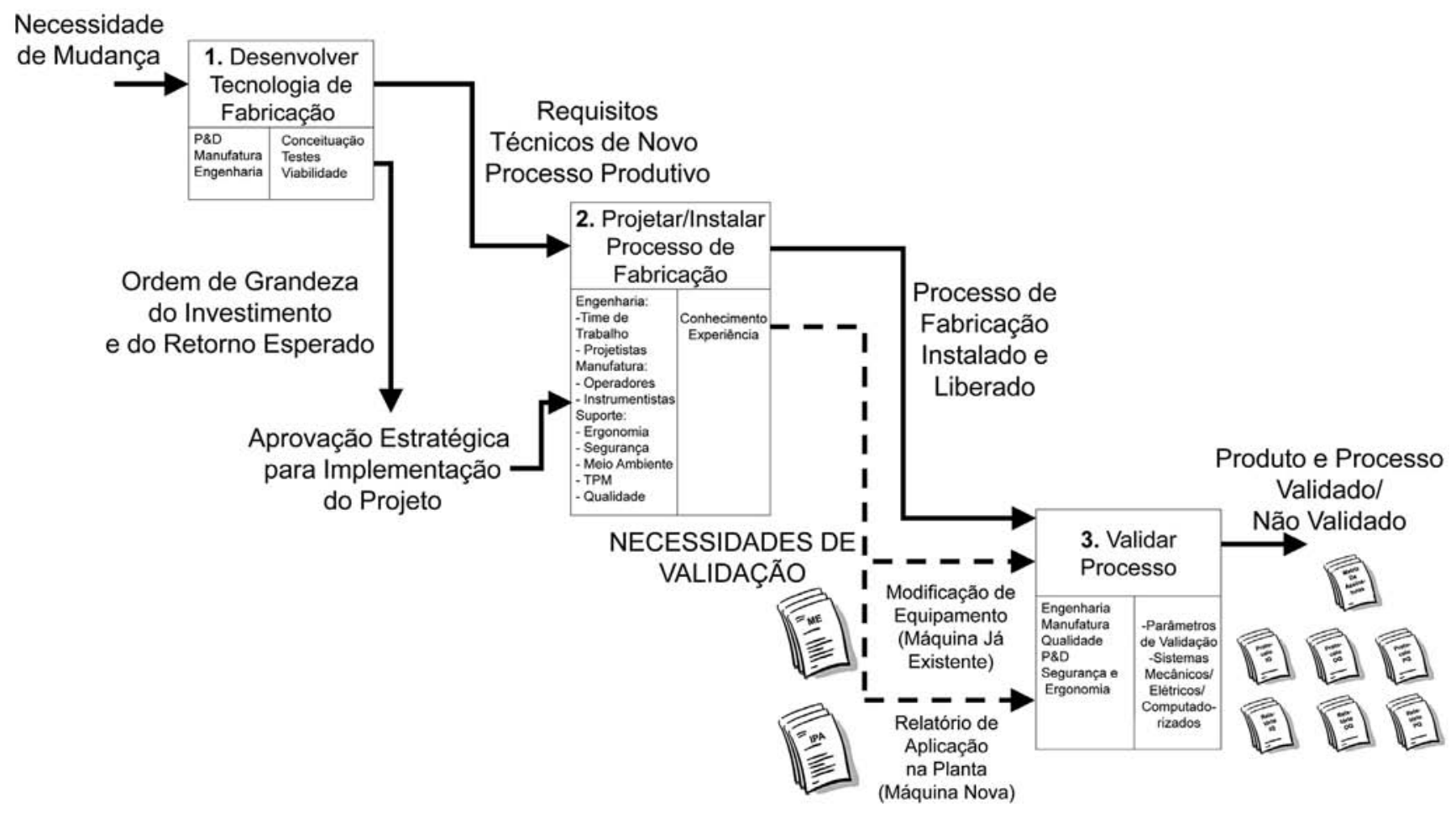

Figura 1: Fases do processo de desenvolvimento dos meios de manufatura da empresa segundo a metodologia de modelagem utilizada. 
tos de operação, como segurança, manutenção, treinamento a operadores, etc.). Na segunda parte, a preocupação é testar esse processo de fabricação frente às especificações técnicas dos produtos, ou seja, verificar se o processo de fabricação consegue obter os produtos dentro das especificações e padrões de qualidade.

As demais atividades do PDP não serão apresentadas, pois não fizeram parte do escopo do estudo. A íntegra do modelo de PDP elaborado durante a pesquisa de campo contém vários gráficos similares à Figura 1, cada qual descrevendo as atividades de cada etapa apresentada na Figura 1 ( $2^{\circ}$ nível da modelagem). De maneira recorrente, foi elaborado um diagrama para cada uma das atividades presentes nos diagramas do nível 2 (3ํㅡível da modelagem). Ao todo, foram identificadas 84 atividades, representadas em 10 diagramas e 22 versões até se atingir o modelo final.

\subsection{Oportunidades de Melhoria e Soluções}

Os resultados obtidos com o mapeamento do processo foram organizados em tópicos denominados "Oportunidades de Melhoria”, um rótulo escolhido em comum acordo entre pesquisador e os participantes da pesquisa. Cada oportunidade de melhoria, descrita a seguir, representa uma disfunção, cuja solução pode melhorar o desempenho da introdução do produto na fábrica.

\subsubsection{Visão Departamental e Comunicação Ineficiente}

A análise do modelo de referência, relatos e a reunião final de validação com os profissionais indicam um foco na visão departamental. Cada etapa do processo é vista como responsabilidade de uma ou duas áreas funcionais específicas. Não há um time de projeto ou gestor que acompanhe o projeto ativamente ao longo das etapas de introdução do produto na manufatura. Frases do tipo: "isto não é responsabilidade nossa" ou "isto é definido por P\&D" foram coletadas em vários momentos pelo pesquisador.

Como conseqüência, os problemas se acumulam. Entre uma fase e outra, as áreas funcionais recebem e entregam "pacotes fechados". A Engenharia de Manufatura começa a desenvolver o projeto de um equipamento a partir de um conjunto de dados originados no P\&D, sem interagir de maneira significativa. O mesmo ocorre na integração engenharia de manufatura e produção. Os últimos possuem um profundo conhecimento dos problemas envolvidos na obtenção de cada produto, em termos de custo e esforço de manutenção, perdas de matérias-prima, tempos de set-up, e etc.

$\mathrm{Na}$ falta de uma interface bem definida e processos sistemáticos para registro e coleta dessas informações, os profissionais de engenharia de manufatura deixam de receber esses dados de entrada em momentos importantes. Uma percepção corrente, reproduzida verbalmente por diferentes profissionais, é a de que a produção não considera o envolvimento no desenvolvimento dos equipamentos como sua responsabilidade.

Há, ainda, a interface entre as áreas de Qualidade e Engenharia de Manufatura. A Qualidade gerencia todas as reclamações de praça recebidas, e identifica as características técnicas do processo produtivo que as originou. Porém, não há um canal para compartilhá-las com a engenharia de manufatura, de maneira a garantir o desenvolvimento de conceitos que eliminem problemas recorrentes.

Um complicador adicional é a segunda oportunidade de melhoria identificada: a comunicação ineficiente entre as áreas funcionais. A etapa de 'Desenvolvimento de Processos de Fabricação' é realizada, de maneira relativamente isolada, pela Engenharia de Manufatura. Ela tem pouca ação sobre vários aspectos externos e entradas (input) que influenciam no resultado do seu trabalho. Por outro lado, interage de maneira tímida com as demais áreas funcionais.

Um aspecto interessante é o de que as conseqüências negativas da visão funcional e falta de comunicação se acumulam em um ponto preciso do PDP da empresa: a fase de "Validar Processo". É o momento do "Desenvolvimento de Processos de Fabricação" no qual cada área funcional tem o poder de "frear" a entrega de um equipamento desenvolvido (e a entrada de um produto no mercado) se qualquer dos aspectos que lhe cabe zelar não for satisfeito. Isso se dá por meio do documento de validação, que precisa ser assinado pelos responsáveis de todas as áreas. Em praticamente todos os desenvolvimentos, os problemas são discutidos neste ponto, quando o equipamento já foi desenvolvido e se encontra no chão-de-fábrica. Mudanças nesse estágio são caras e certamente incorrem em algum tipo de retrabalho. Portanto, os problemas tornam-se evidentes apenas quando esforço e investimentos já foram gastos, o que cria grandes cargas de retrabalho e estresse.

\subsubsection{Falta de registro do conhecimento na engenharia de manufatura}

Outra oportunidade de melhoria identificada diz respeito à capacidade técnica de garantir que as melhorias nos produtos sejam reutilizadas nos novos projetos. Não existem práticas formais institucionalizadas para a documentação e compartilhamento do conhecimento gerado.

Por exemplo, dois projetos diferentes (com equipes distintas) estavam sendo realizados concomitantemente e deveriam gerar máquinas semelhantes. Uma característica das máquinas é a existência de esteiras que movimentam os produtos de uma estação de trabalho a outra durante sua fabricação. São itens significativos no custo total da máqui- 
na, sem os quais não há como produzi-las. Cada máquina possui um conjunto de esteiras e ambas foram montadas ao mesmo tempo utilizando-se esteiras diferentes, quando, do ponto de vista tecnológico, poderiam ser iguais. Isso facilitaria o processo de manutenção (podendo inclusive reduzir a quantidade deste item no estoque) e teriam diminuído o custo e esforço no projeto. Embora o problema tenha sido detectado pelas equipes, não foi registrado. mento na rotina da fábrica, atividade que não é realizada de maneira sistemática na empresa.

O planejamento das paradas de produção, seja para testes em equipamentos atuais, seja para a instalação de novos equipamentos, é deficiente. O resultado é um tempo aquém do necessário, gerando a introdução de processos instáveis; conseqüentemente, perdas significativas de matéria-prima e redução da eficiência. As entrevistas com membros da produção identificaram um sentimento de que a Engenharia realiza suas modificações, encerra o projeto e a Fábrica é obrigada a absorver os problemas decorrentes.

A falta de critérios e regras, claras e negociadas, de quando um equipamento recém-desenvolvido pode ser considerado oficialmente entregue à Fábrica é outra fonte de problemas nesta interface. A em-

A padronização de melhores práticas de projeto poderia ter evitado esse erro e uma base de lições aprendidas poderia eliminar a sua ocorrência futura. A dificuldade de comunicação apresentada no item anterior também contribuiu. Práticas de gestão do conhecimento seriam úteis.

Outro exemplo ocorreu durante o desenvolvimento de uma nova faca para um produto (absorvente higiênico) do tipo "noturno". Considerando a característica cilíndrica da faca, o engenheiro projetou-a proporcionalmente menor que a dimensão do produto, pois, com o efeito do giro, a faca acabaria cortando o material em uma dimensão maior. Apesar do uso correto do conceito, a proporção foi erroneamente especificada. Iniciada a produção, os produtos resultantes ainda estavam com dimensões maiores. A solução foi fabricar uma faca nova, ainda menor que a primeira, compromentendo financeiramente o projeto devido ao alto custo envolvido no item. Recursos humanos, críticos naquele momento, foram desperdiçados na tarefa. A questão técnica não é a mais importante neste exemplo, até porque erros são fontes importantes de aprendizados no processo de desenvolvimento de produtos. Chama atenção a inexistência de mecanismos para disseminar esse tipo de conhecimento (como design guides internos, por exemplo), relevantes para todos os envolvidos.

\subsubsection{Deficiências na validação do produto pelo chão de fábrica}

Durante o estudo, detectaram-se vários conflitos entre as áreas de Engenharia de Manufatura e Produção decorrentes dos critérios de validação dos projetos. A causa principal foi o planejamento dos impactos dos projetos de desenvolvi- presa possui uma série de critérios e diversos procedimentos formais a serem seguidos. Porém, eles não eram discutidos ou priorizados em conjunto, fazendo com que determinadas especificações fossem identificadas e comunicadas para a engenharia de manufatura após o fim do projeto.

Por exemplo, a área de engenharia de manufatura recebeu um escopo do projeto com ênfase em especificações de custo, desempenho operacional e outras características relavantes do ponto de vista do consumidor final. Durante o processo de validação, porém, novas questões foram adicionadas, igualmente relevantes, como segurança do trabalho e ergonomia da máquina; não especificadas no "escopo incial do projeto".

Surgiram então os conflitos, pois neste momento a Engenharia de Manufatura desejava encerrar o projeto e entregar a máquina rapidamente, enquanto a Fábrica buscava garantias de que o equipamento estivesse na melhor condição possível.

Uma das estratégias utilizadas pela fábrica para garantir o recebimento do equipamento em uma condição considerada ideal, eficiência operacional e segurança, é utilizar o processo de validação (que, como citado anteriormente, tem o poder de "frear" a entrega), adiando o seu aceite. Esta solução garante a qualidade do projeto, mas traz um desgaste e perda de tempo nos conflitos internos entre as áreas.

A força do processo de validação dentro da empresa se deve aos requisitos de normas de qualidade, em especial à regulamentação do FDA (Food and Drug Administration) que exige, entre outros, a validação (comprovação) da capabilidade do processo para que o produto possa ser fabricado.

Há uma forte cultura interna em torno deste processo de validação. $\mathrm{Na}$ verdade, segundo a avaliação realizada pelo 
grupo, este é um dos pontos fortes do PDP da empresa. O problema está no fato de que as decisões e a identificação dos problemas se acumulam nesta fase, quando a máquina já está pronta para entrar em operação e as mudanças são custosas.

Além disso, identificou-se a existência de especificações inadequadas. É o caso de certas especificações dimensionais e metas rígidas de perdas de material que freiam o início da produção, às vezes inviabilizando o lançamento.

Há também conflitos de ordem financeira nesta interface. As estimativas de tempo de máquina parada e recursos (para matéria-prima e demais gastos envolvidos) nos testes (debugging/validação) são deficientes e é comum a falta de recursos no final do projeto. Isso aumenta a tensão e o conflito entre as duas áreas funcionais, engenharia de manufatura e produção, não sendo raro a fábrica absorver parte dos custos que simplesmente não estavam previstos (nem no orçamento do projeto nem nos centros de custo da fábrica).

\subsubsection{Equipamentos projetados com problemas ergonômicos e/ou de segurança}

Esta oportunidade de melhoria é evidenciada pelos conflitos entre a área de Engenharia de Manufatura e Segurança, Ergonomia e Meio Ambiente. A participação da última delas se dá no final do processo, quando o cronograma do projeto está no fim e o orçamento foi gasto. É o caso, por exemplo, de uma máquina com um ponto de abastecimento de matériaprima numa altura elevada, quando poderia estar localizada próximo ao chão para facilitar a alimentação de itens pesados, evitando riscos ocupacionais e gastos com prevenção.

Há um programa de prevenção de acidentes e segurança por meio de projetos em disciplinas, mas problemas como este ainda são freqüentes. Considerando-se a importância, legislações e punições, cada vez mais duras e severas, com relação a esta questão, justifica-se o desenvolvimento de práticas e mudanças no PDP da empresa visando um tratamento mais adequado.

A segunda razão principal para esse tipo de problema são os orçamentos para projetos de desenvolvimento. Desenvolver um equipamento com risco zero em todos os fatores de segurança, ergonomia e meio ambiente pode significar custos adicionais. Essa discussão não é realizada de maneira profunda no planejamento inicial dos projetos.

\subsubsection{Definição das especificações técnicas e de pesquisa}

Um dos principais motivos de conflito entre as áreas funcionais está nas especificações técnicas do produto. Os problemas acontecem entre as áreas de Engenharia de Manufatura, P\&D e Qualidade. Empregam-se valores numéricos e tolerâncias dimensionais e de peso não condizentes com a variabilidade do processo e com a própria dificuldade técnica de se medir tais produtos.

Um exemplo emblemático é uma especificação de fragrância proposta para um produto, cujo valor nominal e tolerâncias eram da ordem de centésimos de grama por produto. Considerando-se a velocidade de fabricação na casa de centenas de produtos por minuto, percebe-se a impossibilidade de se garantir o atendimento a uma especificação desse tipo. Mesmo que se possa garantir tecnologicamente o atendimento a ela, o custo provavelmente será tão elevado a ponto de tornar o projeto inviável.

Milhares de produtos são descartados e lançamentos são atrasados quando especificações desse tipo não são atendidas. Podem ser considerados desperdícios, dado que, na maioria das vezes, análises mais profundas conduzidas por $P \& D$ e engenharia de manufatura identificam que é possível estabelecer um nível de tolerância maior e adequado, isto é, que, mesmo aceitando uma maior variabilidade, ainda assim se garantem o desempenho e a segurança do produto.

\subsubsection{Solução de problemas durante o início da produção}

As falhas observadas anteriormente conduzem a um processo de validação por vezes traumático. Deve-se lembrar que a validação depende da solução de todas as não-conformidades, um aspecto fortemente institucionalizado dado o grau de excelência e exigências internas da empresa. Assim, há um esforço concentrado para eliminá-las rapidamente. Tarefas são definidas e delegadas de maneira informal e muitas ações são disparadas sem o devido cuidado e orientação necessários.

O modelo geral de documentação e testes, empregado para conduzir a validação, segue os requisitos do Food and Drugs Administration (FDA), rígido quanto à comprovação por meio de documentos. Talvez por isso, o enfoque da validação é fortemente burocrático. A maneira como abordar o problema, a divisão de tarefas, a formação de equipes e a análise da situação não são realizadas de maneira sistemática.

Um processo formal para a solução desses problemas, que classificasse as não-conformidades e as tratasse em projetos de melhoria, poderia diminuí-los e tornar as ações de acertos (debugging) mais eficientes. Ou mesmo, a integração com os projetos de melhoria do tipo seis sigma adotados pela área de manufatura é alternativa interessante.

\subsection{Soluções definidas pela equipe}

Conforme descrito no item 4.3, passo 8 do método, as análises foram apresentadas aos vários envolvidos em uma reunião conjunta. O grupo confirmou as oportunidades de melhoria e identificou ações com o objetivo de solucioná-las, resumidas no Quadro 1. 
Nota-se que as soluções contemplam o receituário proposto pela teoria mais recente de gestão do desenvolvimento de produtos, envolvendo: implantação de Phase-Gates, FMEA e trabalho em times multifuncionais; definição de objetivos e escopo detalhado no início do projeto de engenharia de máquinas; definição de atividades para alcançar os objetivos e respectivas responsabilidades; e também reuniões de acompanhamento - atualizações, revisões e ações corretivas. Aliás, a empresa já vinha trabalhando esses tópicos, dado que estão contemplados no modelo de processo de desenvolvimento de produtos oficial.

Outro ponto a se notar é o fato de as ações serem eminentemente voltadas para a inspeção, isto é, para controle. Em geral, o foco é estabelecer apropriadamente os critérios de

\section{Quadro 1: Resumo das ações identificadas pela equipe.}

\begin{tabular}{|c|c|c|}
\hline $\begin{array}{l}\text { Item do } \\
\text { texto }\end{array}$ & Oportunidade de Melhoria & Possíveis soluções identificadas \\
\hline 6.2 .1 & Visão departamental & $\begin{array}{l}\text { Reforçar Visão de Processo: } \\
\text { • Formação de Times Multifuncionais } \\
\text { • Estruturação do Processo - Desenvolver Processos de Fabricação }\end{array}$ \\
\hline 6.2 .1 & $\begin{array}{l}\text { Comunicação ineficiente } \\
\text { entre diferentes áreas } \\
\text { funcionais }\end{array}$ & $\begin{array}{l}\text { Formação de um Time de Projeto Multifuncional (Fábrica, Engenharia, Segurança, etc.) } \\
\text { Divisão do processo de "Desenvolvimento de Processos de Fabricação" em fases e } \\
\text { inserção de pontos de verificação e alinhamento (Phase-Gates) }\end{array}$ \\
\hline 6.2 .2 & $\begin{array}{l}\text { Falta de registro do } \\
\text { conhecimento gerado } \\
\text { durante a realização dos } \\
\text { projetos (lições aprendidas) }\end{array}$ & $\begin{array}{l}\text { Utilizar FMEAs de processo } \\
\text { Criar uma base de conhecimentos ou sistema de registro e divulgação de lições } \\
\text { aprendidas } \\
\text { Garantir que conhecimentos adquiridos durante a experiência do projeto sejam } \\
\text { documentados e divulgados (criação de design guides internos) }\end{array}$ \\
\hline 6.2 .3 & $\begin{array}{l}\text { Baixo estudo dos impactos } \\
\text { do desenvolvimento no dia- } \\
\text { a-dia da Fábrica }\end{array}$ & $\begin{array}{l}\text { Envolver a fábrica desde as etapas iniciais do projeto } \\
\text { Divisão do Projeto de “Desenvolvimento de Processos de Fabricação” em fases e } \\
\text { inserção de pontos de verificação e alinhamento (Phase-Gates) }\end{array}$ \\
\hline 6.2 .3 & $\begin{array}{l}\text { Falta de regras claras para } \\
\text { entrega de equipamentos da } \\
\text { Engenharia para Fábrica }\end{array}$ & $\begin{array}{l}\text { Criar uma lista de verificação de critérios para a validação única, contendo todas as } \\
\text { dimensões } \\
\text { Inserir pontos de negociação dos critérios de validação no início do processo }\end{array}$ \\
\hline 6.2 .3 & $\begin{array}{l}\text { Conflito com fábrica por } \\
\text { custos e tempo de máquina } \\
\text { parada para testes }\end{array}$ & $\begin{array}{l}\text { Inserir custos de máquina parada e debugging no orçamento do projeto } \\
\text { Aprimorar o planejamento e cronograma do projeto e negociar com fábrica tempos de } \\
\text { testes e debugging }\end{array}$ \\
\hline 6.2 .4 & $\begin{array}{l}\text { Atendimento aos requisitos } \\
\text { ergonômicos e de segurança }\end{array}$ & $\begin{array}{l}\text { Envolver Segurança desde as etapas iniciais do projeto } \\
\text { Criar pontos de Verificação e Acompanhamento (Phase-Gates) }\end{array}$ \\
\hline 6.2 .5 & $\begin{array}{l}\text { Dificuldade na especificação } \\
\text { técnica dos produtos }\end{array}$ & $\begin{array}{l}\text { Delinear interface com P\&D - produtos devem ser especificados dentro do que o } \\
\text { processo produtivo pode fazer e da percepção de qualidade da usuária }\end{array}$ \\
\hline 6.2 .6 & $\begin{array}{l}\text { Não conformidades } \\
\text { encontradas durante a } \\
\text { Validação }\end{array}$ & $\begin{array}{l}\text { Garantir que os planos de ação sejam criados pelo Time do Projeto (multifuncional) e } \\
\text { cumpridos } \\
\text { Criar um sistema visual e público de status das Validações e dos projetos disparados por } \\
\text { não conformidades }\end{array}$ \\
\hline 6.2 .6 & $\begin{array}{l}\text { Documentação excessiva } \\
\text { para a Validação }\end{array}$ & $\begin{array}{l}\text { Envolver as diversas áreas funcionais na confecção dos documentos } \\
\text { Utilizar padrões e normas com bom senso para evitar que muitos documentos sejam } \\
\text { gerados }\end{array}$ \\
\hline 6.2 .6 & $\begin{array}{l}\text { Desenvolvimento/ Debugging } \\
\text { / Validação realizados } \\
\text { durante a etapa de Validar } \\
\text { Processo }\end{array}$ & $\begin{array}{l}\text { Aprimorar o planejamento e o cronograma do projeto e negociar com fábrica tempos de } \\
\text { testes e debugging } \\
\text { Envolver melhor as diversas áreas funcionais na confecção dos documentos }\end{array}$ \\
\hline
\end{tabular}


validação e verificá-los. Apenas duas (2) ações de caráter preventivo foram identificadas: a introdução da técnica FMEA e o trabalho em times. A utilização das recentes teorias sobre otimização de projetos, como o Design for Six Sigma e a Gestão por Parâmetros Críticos (discutidos na revisão), não foi mencionada, um indício de que tais tipos de ação ainda não são diretamente relacionados com a validação na visão dos profissionais. A relação entre otimização do projeto e validação era pouco explorada, na época do estudo.

A escassez de soluções para apoiar o projeto e validação de meios de produção, identificada na revisão bibliográfica, foi observada também na prática. Quando os profissionais buscaram soluções para as oportunidades de melhoria, não encontraram muitas opções de caráter preventivo. Indicando, portanto, uma lacuna de métodos e técnicas na área, questionada pelos profissionais.

\section{CONSIDERAÇÕES FINAIS}

O artigo aponta vários aspectos problemáticos em relação às atividades de projeto do processo de fabricação no PDP de uma empresa de alto volume. As soluções propostas na literatura não parecem suficientes. Basta verificar que, no caso estudado, foram identificadas várias oportunidades de melhoria e poucas ferramentas capazes de solucioná-las.

Outro aspecto é que as soluções identificadas são fortemente voltadas para o controle, ações, portanto, "reativas". O caso acompanha, portanto, a limitação encontrada nos livros clássicos, que não se aprofundam no detalhamento dos processos de fabricação do PDP, apesar de citarem a importância desta etapa. Não foi possível identificar práticas mais atuais de otimização do projeto, tais como o Design for Six Sigma (DFSS), Projeto para a Manufatura e Montagem (DFSS) e a Gestão de Parâmetros Críticos (CPM).

O discurso encontrado na empresa é coerente com a filosofia dessas novas ferramentas (otimizar os projetos), mas no momento de definir ações práticas os profissionais encontraram dificuldades em estabelecer soluções concretas, capazes de viabilizar essa meta. Trata-se do mesmo viés encontrado na literatura. Os trabalhos citam a importância, mas não detalham ferramentas ou soluções capazes de apoiar o projeto dos meios de produção.

O caso demonstra ainda que o estabelecimento de critérios para a validação é outro aspecto a ser revisto. Apesar do nível elevado de formalização e documentação, ainda há divergências. Em especial, durante a decisão de qual tipo de modificação deve ou não exigir uma revalidação, ou seja, quais modificações na máquina necessitam de um novo processo de validação. Como criar critérios para a validação de processos de fabricação de novos produtos, mais simples e efetivos, pode ser uma interessante contribuição e tema de pesquisa.

\section{Conclui-se que o projeto e a validação de meios de da área de gestão de desenvolvimento de produto, comparando-se em relação ao que vem sendo feito.}

Alguns temas para pesquisas futuras originados do trabalho são: relação entre métodos do DFSS e critérios para a validação dos produtos; desenvolvimento de uma metodologia para melhoria ou eliminação de falhas de produtos durante os acertos de máquinas; aplicação de DFSS na validação e melhoria do produto na fábrica, estudo da integração entre as atividades do processo de desenvolvimento de produto e programas de melhoria do chão de fábrica; uma proposta de estrutura de Phase Gates específica para empresas de alto volume e contínuas; proposta de métodos e critérios mais simplificados de validação, que satisfaçam as exigências das agências reguladoras e sejam seletivos, evitando esforços duplicados (revalidação); propostas de sistemas de armazenamento de melhores práticas integrados com a ação de identificação de problemas (debugging).

Uma contribuição adicional do trabalho está na metodologia empregada. O resultado da aplicação de uma ferramenta de modelagem de processo como instrumento de pesquisa mostrou-se extremamente frutífero e auxiliou na realização de um diagnóstico de grande imersão na realidade. Seu emprego, combinado com métodos tradicionais, possibilitou uma organização mais eficiente dos dados gerados por outros instrumentos: entrevistas, análise documental e observação participante.

Conclui-se que o projeto e a validação de meios de fabricação merecem mais atenção dos pesquisadores da área de gestão de desenvolvimento de produto, comparando-se em relação ao que vem sendo feito. Em um contexto de demanda crescente pelo atendimento a normas e requisitos legais estritos (seja de legislação, agências reguladoras ou certificadoras), as empresas de alto volume necessitam de ferramentas cada vez mais eficientes para validar o desenvolvimento e introduzir os produtos nas unidades fabris. 


\section{Artigo recebido em 08/08/2006 Aprovado para publicação em 03/06/2008}

\section{REFERÊNCIAS}

BAXTER, M. Projeto de produto: guia prático para o desenvolvimento de novos produtos. São Paulo: Edgard Blücher, 1998.

BENEDICTS, C. C., AMARAL, D. C.; ROZENFELD, H. Avaliação dos principais métodos e ferramentas disponíveis para a modelagem o processo de desenvolvimento de produto. In: IV Congresso Brasileiro Gestão e Desenvolvimento de Produtos - Gramado, RS, Brasil, Anais, 2003.

CHRISSIS, M.B.; KONRAD, M.; SHRUM, S. CMMI: guidelines for process integration and product improvement. Boston: AddisonWesley, 2003.

CLARK, K. B.; FUJIMOTO, T. Product development performance: strategy, organization and management in the world auto industry. Boston-Mass., Harvard Business School Press, 1991.

CLAUSING, D. Total quality development. New York: ASME Press, 1994.

COOPER, R.G. Winning at new products: accelerating the process from idea to launch. Reading, MA: Perseus Books, 1993.

CREVELING, C. M.; SLUTSKY, J. L.; ANTIS JR., D. Design for Six Sigma. In technology and prod- uct development. Upper Saddle River: Prentice Hall, 768 p., 2003.

CRUZ, T. Sistemas, métodos \& processos. São Paulo: Atlas, 2003.

GIL, A. C. Como elaborar projetos de pesquisa. 3ed. São Paulo: Atlas, 1991.

MARCA, D.; MCGOWAN, C. L. IDEFO/SADT: business process and enterprise modeling San Diego: Ecletic Solutions Corporation, 392p., 1997.

MÜLLER, M. H.; FAIRLIE-CLARKE, A. C. The evaluation of manufacturing issues in the product development process. Journal of Materials Processing Technology, v. 50, n. 138, p. 2- 8, 2003

OZER, M. A Survey of new product evaluation models. Journal of Product Innovation Management, v. 16, p. 77-94, 1999.

PARK, H. G.; BAIK, J. M. Enhancing manufacturing product development through learning agent system over internet. Computers \& industrial Engineering, v. 37, p. 117-120, 1999.

PHADKE, M.S. Quality engineering using robust design. Englewood Cliffs, N.J.: Prentice Hall, 1989.
PUGH, S. Total design: integrated methods for successful product engineering. Reading, $\mathrm{HA}$ : Addison, 1978.

ROZENFELD, H. et al. Gestão de desenvolvimento de produtos: uma abordagem para a melhoria de processos. São Paulo: Saraiva, 2006.

SLACK, N.; CHAMBERS, S.; HARLAND, C.; HARRISON, A.; JOHNSTON, R. Administração da produção. São Paulo: Atlas, 1997.

ULLMAN, D. G. The mechanical design process. New York: McGraw-Hill International Editions, 1997.

ULRICH, K. T.; EPPINGER, S. D. Product design and development. New York: McGraw-Hill, 1995.

VERNADAT, F. B. Enterprise Modeling and Integration: Principles and Applications. London: Chapman \& Hall, 1996.

WHEELWRIGHT, S. C.; CLARK, K. B. Managing new product and process development: text and cases. New York: The Free Press, 1993.

YIN, R. K. Estudo de caso: planejamento e método. Porto Alegre: Bookman, 2001.

\section{SOBRE OS AUTORES}

\section{Felipe Botta Tarallo}

Whirlpool S.A.

End.: Rua Dona Francisca, 7200 - Distrito Industrial - CEP 89219-900 - Joinville, SC - Brasil

Tel.: (47) 3803-4098

E-mail: felipe_b_tarallo@whirlpool.com / felipetarallo@yahoo.com.br

\section{Daniel Capaldo Amaral}

Departamento de Engenharia de Produção

Escola de Engenharia de São Carlos - USP

End.: Rua do Trabalhador Sãocarlense, 400 - CEP 13566-590

Tel.: (16) 3373-8289 / Fax.: (16) 3373-8235

E-mail: amaral@sc.usp.br 